\title{
LA RELACION JURIDICO-LABORAL EN QUE INTERVIENEN LAS CORPORACIONES LOCALES COMO EMPRESARIOS \\ (La sentencia del Tribunal Central de Trabajo de 13 de junio de 1975)
}

352.712: 340.142

\author{
por \\ Enrique Barrero Gonzalez \\ Letrado del Ayuntamiento de Sevilla
}

SUMARIO: I. PLANTEAMIENTO DEL TEMA Y CUESTION DE HECHO.-II. LOS DERECHOS ADQUIRIDOS. ESPECIAL REFERENCIA A LA LEGISLACION LABORAL.-III. LA CONCESION TACITA DEL DERECHO. EL CASO CONCRETO DE LA ADMINISTRACION LOCAL.-IV. LOS PRONUNCIAMIENTOS DE LA SENTENCIA.V. CONCLUSION.

\section{PLANTEAMIENTO DEL TEMA Y CUESTION DE HECHO}

El tema que me propongo desarrollar en este comentario gira en torno a la sentencia dictada por la Sala Tercera del Tribunal Central de Trabajo, en 13 de junio de $1975^{*}$, poniendo fin a un conflicto colectivo en el que fue parte el Ayuntamiento de Sevilla y que promovió determinado grupo de personal laboral de las plantillas de este Ayuntamiento.

Intentaré exponer los hechos en la forma más breve y clara que me sea posible.

El Ayuntamiento prestaba, por sí mismo, de manera directa, el

* Formaban Sala los Iltmos. Sres. Salamanca Martfo, Bartolomé Sanz y Martn Corraa. Fue Ponente D. Francisco José Salamanca Martin. 
servicio de limpieza de las Escuelas Nacionales de la ciudad. Para ello tenía una plantilla de limpiadoras afectas a tales Colegios.

En un momento determinado, el Ayuntamiento decidió adjudicar el servicio mediante concurso público, a una Empresa privada, propósito en el que, sin duda, influyó el escaso rendimiento de la plantilla y las dificultades que entraña, para un organismo público, el adecuado control de tales servicios. Fue condición expresa del concurso que la Empresa adjudicataria se hiciese cargo de la relación laboral con las limpiadoras y les respetase íntegramente sus derechos adquiridos, de tal forma que no sufriesen perjuicio alguno. Con esta salvedad, el indicado personal continuaría rigiéndose en cuanto a sus derechos y obligaciones, por el Reglamento de Personal no Funcionario del Ayuntamiento, el cual, entre otras cosas, señala una jornada laboral de ocho horas diarias. El propio Ayuntamiento tenía expresamente dispuesto, en virtud de acuerdo plenario, que dicha jornada legal regiría para este concreto personal de que se trata.

La Empresa adjudicataria de la concesión, al comenzar la prestación del servicio, ordenó a las limpiadoras un trabajo de ocho horas diarias, consecuente con lo anteriormente indicado.

Pero las operarias mostraron su disconformidad y consiguieron demostrar que desde fecha no determinada con exactitud, pero bastantes años antes de que la Empresa asumiese el servicio, venian prestando una jornada laboral de cinco horas diarias sin oposición por parte del Ayuntamiento, que les pagaba como si trabajasen las ocho horas previstas reglamentariamente.

Si bien no pudieron demostrar, por el contrario, que esta jornada reducida se hiciese con expreso consentimiento del Ayuntamiento, que más bien parecía que ignoraba lo que ocurría en el servicio, al efectuarse el trabajo en centros dispersos o alejados de la Casa Consistorial.

El conflicto colectivo se planteó sobre los expresados hechos. Las limpiadoras pretendieron persistir en el disfrute del horario reducido y la Empresa y el Ayuntamiento se mantuvieron firmes en la necesidad de cumplir el horario reglamentario, poniendo fin a las corruptelas existentes.

Fácilmente se advierte que la resolución del litigio tenía que girar, fundamentalmente, en torno a dos cuestiones. De una parte, si las limpiadoras habían adquirido derecho a permanecer en el horario 
reducido, en virtud de la situación de hecho creada contra la voluntad municipal. De otra, si la circunstancia de que el patrono fuese, en este caso, un Ayuntamiento influiría de alguna manera en la solución del problema.

La sentencia de la Sala Especial de Conflictos Colectivos del Tribunal Central del Trabajo zanjó la cuestión con interesantes afirmaciones.

Pero antes de ver el desenlace, procede que hagamos una incursión en torno a los conceptos jurídicos barajados.

\section{LOS DERECHOS ADQUIRIDOS. ESPECIAL REFERENCIA A LA LEGISLACION LABORAL}

1. Ya se sabe que el concepto de «derecho adquirido» es extraordinariamente polémico. Alejandro NIETo comenzaba un trabajo. que dedicó al tema (1) citando la siguiente afirmación de DuGUIT: Nadie ha sabido nunca qué es un derecho adquirido. En el mismo sentido, entiende Garcta-Trevijano (2) que se trata de un concepto de concreción teórica sumamente difícil. Circunstancia que fue tenida en cuenta hace ya casi un siglo por los redactores de la exposición de motivos de la edición reformada del Código civil, mandada publicar por Real Orden de 29 de julio de 1889, al afirmar que se estimaba peligrosa la definición abstracta de los derechos adquiridos, por ser «la definición y la determinación de estos derechos uno de los problemas más difíciles de la ciencia de la legislación» (3).

Los derechos adquiridos -nacidos como concepto propio de la Teoría General del Derecho, pero refugiados fundamentalmente en el campo del Derecho funcionarial (4)- están siendo en la actualidad objeto de fuertes embates por parte de la doctrina, hasta el punto de que se les señala frecuentemente como uno de los obstáculos principales de la reforma de la función pública (5), contraponiéndolos al poder de la Administración de organizar y reorganizar sus servicios.

(1) aLos derechos adquiridos de los funcionarios», RAP, núm. 39, págs. 241 y ss.

(2) Tratado de Derecho administrativo, tomo III, volumen I, pág. 452.

(3) Código civil. Edición Instituto Nacional de Estudios Jurídicos, 1967, pág. 36.

(4) NARBEL: «Les droits acquis des fonctionnaires», Lausanne, 1957 (RAP, 31, página 387).

(5) GaRRIDo Falla: aNecesidad y obstáculos de la reforma de la función pública», en $D A$, núm. 16, pág. 29. 
Ahora bien, sin necesidad de acudir a teorías extremas, tendentes a una progresiva desvalorización de estos derechos, claudicantes frente al poder organizatorio de la Administración -hoy, sin embargo, de rigurosa actualidad-, es lo cierto que aún admitiendo la existencia y la vigencia del concepto, se hace necesario que sea objeto de una adecuada comprensión.

El problema de los derechos adquiridos está íntimamente ligado al de la retroactividad de las normas (6), ya que constituyen situaciones jurídicas consolidadas conforme a la ley del tiempo en que se produjo el hecho idóneo para hacerlos nacer y entrar a formar parte del patrimonio del interesado. De ahí que, como señala correctamente el Reglamento de Funcionarios de Administración Local, en sus disposiciones adicionales, no constituyan derecho adquirido las simples expectativas, que en todo caso tienen que ceder ante la vigencia de la nueva ordenación promulgada (7).

De aquí nace, pues, un primer condicionamiento, en el sentido de que el derecho que se invoque ha de haberse consolidado antes de la modificación del estatuto funcionarial.

Existen, además, otros condicionamientos, fundamentalmente en cuanto al modo de adquisición de estos derechos.

$\mathrm{La}$ adquisición tiene que ser legítima, como consecuencia de un acto expreso de la Administración, sin que valgan a la adquisición de tales derechos determinadas prácticas, abusos o corruptelas meramente tolerados (8). Han de provenir, por tanto, de un legí-

(6) Garcta-Trevijano: Obra citada, pág. 457. En la redacción originaria del Código civil la mención del respeto a los derechos adquiridos estaba contenida en un segundo párrafo del artículo 1.976. En la edición reformada, mandada hacer por Ley de 26 de mayo de 1889, se incluye ya en las disposiciones transitorias, al ser conscientes los redactores de que se trata de un problema de retroactividad de normas (Código civil, edición citada, pág. 449).

(7) Existe un supuesto intermedio entre derecho adquirido y mera expectativa, que induce a confusión. La disposición transitoria cuarta del Código civil se refiere a estos supuestos que califica como a acciones y derechos nacidos y no ejercitados* antes de regir el Código, para los que establece reglas especiales. Probablemente por influencia del Código, la disposición adicional primera, tres, del Reglamento de Funcionarios de Administración Local aludió a determinados «derechos adquiridos para el futuro», situándolos entre los aactuales» derechos adquiridos y las simples expectativas que no tienen tal consideración. GoNzÁLZ NiETo critica esta matización, afirmando que no hay razón alguna para diferenciar estos derechos futuros de las simples expectativas ( $a$ Los derechos adquiridos según el Reglamento de Funcionarios de Administración Local», en REvisTA DE EsTUDIos DE LA VIDA LOCAL, núm. 97, pág. 70).

(8) Lo cual constituye, al fin $y$ al cabo, un principio de Derecho que trasciende a todos los órdenes jurídicos; cfr., por ejemplo, el artículo 444 del Código civil. 
timo acto administrativo strictu sensu, si bien entendiendo correctamente, conforme enseña la sentencia de 27 de octubre de 1957 (Aranzadi 3616, Ponente MARTí DEL BuRgo) que «la distinción entre norma y acto administrativo no viene establecida modernamente en función de la generalidad o no de sus destinatarios, sino, en la condición ordinamental de la primera, frente al carácter ordenado del segundo, en el que ciertamente priva lo concreto, singular o particular". Tampoco ha de pensarse que el carácter de legitimidad del acto impida que el derecho adquirido nazca de actos administrativos que hubiesen podido tacharse de irregulares o anulables, puesto que como advierte Garcta-Trevijano, a propósito de la doctrina contenida en el Dictamen del Consejo de Estado de 15 de marzo de 1946, la «doctrina de los derechos adquiridos se conecta con la potestad o no de anulación o revocación de los actos administrativos generadores de aquéllos» (9), con toda la problemática que esta cuestión plantea.

2. Pero, por otra parte, debe tenerse en cuenta que no debemos movernos exclusivamente en el ámbito del concepto de los derechos adquiridos funcionariales, puesto que estamos comentando un caso en el que la relación jurídica establecida era laboral.

En el campo laboral el concepto restringido de derecho adquirido no se da como en el Derecho funcionarial, por la sencilla razón de que la naturaleza de la relación jurídica no es estatutaria, sino contractual. GARCtA-TREVIJANo recoge, en este sentido, la afirmación de NARBEL, de que los derechos adquiridos son una supervivencia de la idea del contrato (10) y afirma que «el problema se plantea en forma distinta a como lo enfoca el derecho del trabajo al tratar la potestad variandi del empresario». En el trabajador no se da una situación de subordinación especial, como en el funcionario, al ser contractual la naturaleza jurídica de su relación de trabajo.

Ciertamente que el Derecho laboral ha sido más generoso en la aceptación de la idea de derecho adquirido, que en este campo ha encontrado aclimatación, bajo la imposición de respeto a las

(9) Obra citada, página 465. Puede verse un estudio general de la irrevocabilidad de los actos administrativos declarativos de derechos en BoQUERA OLIVER: La anulación de oficio de las licencias de edificación, Gabinete de Estudios de la Secretaría General del Ayuntamiento de Sevilla, 1975.

(10) Obra citada, pág. 457. De ahí su desvalorización en una relación jurídica de naturaleza estatutaria. 
condiciones más beneficiosas adquiridas por los trabajadores en el desempeño de sus funciones.

Respeto que se impone no sólo en el campo estrictamente económico (11), sino también en el organizativo, impidiendo la modificación, por cualquier concepto, de las condiciones de trabajo (12).

Ahora bien, también la doctrina laboral ha clamado contra la extensiva aplicación del concepto de "condición más beneficiosa», habiendo afirmado, por ejemplo, Alonso Garcfa (13) que «se está llevando a extremos realmente desproporcionados, conceptuando como condiciones más beneficiosas situaciones que no responden al genuino sentido de dicho principio".

En el mismo sentido se advierte por Alonso Olea un intento de definir los límites de la condición más beneficiosa, incluso expresamente concedida, aludiendo a que «no son admisibles contra las normas de Derecho necesario configuradoras de las estructuras institucionales del Derecho del Trabajo y las generales del Ordenamiento jurídico" (14).

También la condición más beneficiosa tiene que provenir de una adquisición legítima, sin que pueda considerarse como tal, como afirma la sentencia de 24 de junio de 1970 (15) «un largo período de práctica ilegal de la que no puede derivar derecho alguno en orden a su consolidación» (16).

Pero la adquisición legítima puede provenir tanto de un acto expreso del empresario, como de un acto tácito. Procede hacer alusión a este punto, con expresa referencia a la Administración local.

(11) En relación con los funcionarios públicos he visto una interesante sentencia de la Sala de lo Contencioso de la Audiencia de Sevilla, de 30 de junio de 1962 (Ponente, MARTfN Del Burgo), que alude a lo que llamó aprincipio del no retrocesos, o consolidación de cualquier mejora o conquista conseguida por vía legal, dentro del cuadro de percepciones, como remuneración del trabajo personal.

(12) La sentencia del Tribunal Supremo de 30 de mayo de 1972 (Aranzadi 3100) lo expresa así: aSe ha de entender siempre todo ello... (las facultades modificativas de la Empresa), con respeto absoluto a los derechos adquiridos por los productores y además teniendo en cuenta también el respeto a las condiciones más favorables para los mismos».

La sentencia de la Sala de lo Contencioso-administrativo de la Audiencia de Sevilla, de 31 de enero de 1975, afirma que este principio es consustancial con el ordenamiento, incluso por exigencias de los de orden constitucional (recurso 124/74. Ponente: FERnANDEZ Viagas).

(13) Curso de Derecho del Trabajo. Ediciones Ariel. Cuarta edición, pág. 284.

(14) Derecho del Trabajo, Madrid, 1974, pág. 420.

(15) Aranzadi 3433. Ponente, SuArez Manteola.

(16) Esta doctrina es consustancial con elementales principios que rigen el orden jurídico. Por eso mismo, dentro de la Teoría General de Derecho adminis- 


\section{LA CONCESION TACITA DEL DERECHO. EL CASO CONCRETO DE LA ADMINISTRACION LOCAL}

En el apartado anterior hemos presupuesto que el derecho ad. quirido o la condición más beneficiosa ha de derivarse de una adquisición legítima, sin que valgan meras corruptelas. Supuesta tal legitimidad, cualquier condición o derecho adquirido por los trabajadores se incorpora al nexo del trabajo y han de ser respetados, sin que contra ellos valga el ius variandi del empresario.

En cuanto a los derechos adquiridos de los funcionarios hemos mantenido más arriba que tienen que nacer de un acto administrativo, que considera casos concretos, singulares o particulares. Los actos administrativos ya se saben que tienen que ser expresos y regularmente adoptados.

1. Ahora bien, en el Derecho laboral, precisamente por la naturaleza contractual de la relación jurídica, no sólo cabe hablar de voluntad expresa, sino que hay que tener en cuenta igualmente el reconocimiento de las meras situaciones de hecho favorables al trabajador por la pasividad, indiferencia o renuncia a oposición del empresario.

El artículo 9 de la Ley de Contrato de Trabajo, establece «la voluntad de las partes» como una de las fuentes de regulación de dicho contrato, y no cabe duda de que los particulares expresan su voluntad expresa o tácitamente, o sea, en este último caso, mediante silencios a los que la Ley atribuye determinados efectos jurídicos.

En el Derecho privado el consentimiento es tácito, como afirma la sentencia de 24 de mayo de 1975 (17) «cuando del comportamiento de las partes o de sus declaraciones resulta implícita la aquiescencia».

Aunque el Código civil no regula el consentimiento tácito (18), la doctrina se ha encargado de matizar los conceptos. PUIG PeÑa

trativo se establece, por ejemplo, que una actuación no ajustada a derecho no vincula como precedente, ya que ello equivaldría a aprecipitar en cadena una convulsión del sistema jurídicos (puede verse la interesante sentencia de la Sala Quinta de 26 de noviembre de 1975. Ponente, MARTfN DEL. Burgo, que contiene además atinadísimas consideraciones sobre la diferencia existente entre discrecionalidad y conceptos jurídicos indeterminados).

(17) Aranzadi 2104. Ponente, Rull Viluar.

(18) Que sepamos, sólo en el artículo 1.566 se habla de atácita reconducción, y en el 999 de aceptación tácita de la herencia, etc. 
afirma que «el consentimiento libremente emitido, sin vicio de que pueda resentirse, ha de quedar manifestado o exteriorizado oportunamente. Un consentimiento que no se manifiesta es un no consentimiento. Ahora bien, la declaración puede ser expresa, tácita o presunta. La primera es la normal y existe cuando se utiliza para exteriorizarla la palabra hablada o escrita. La tácita existe cuando se realizan ciertos actos que no se dirigen propiamente a exteriorizar una voluntad, pero ésta se infiere de la conducta o comportamiento de una persona. Finalmente la presunta es una ficción que produce efectos determinantes a través de una situación producida» (19).

La Jurisprudencia ha perfilado la doctrina del consentimiento tácito, fundamentalmente a efectos de la causa de resolución del contrato de arrendamiento prevista en el apartado 7 del artículo 114 de la Ley arrendaticia urbana, que faculta al propietario para efectuar la resolución del contrato en el supuesto de realización, sin su consentimiento, de determinadas obras. En general la Jurisprudencia ha negado que mero conocimiento equivalga a consentimiento, matizando el principio qui tacet consentire videtur, en el sentido de que sólo consiente el que calla en el supuesto de que pudiera y debiera haber hablado.

En el Derecho laboral, en cambio, quizá por su carácter tuitivo y por aplicación del principio in dubio pro operario, se ha sido más tolerante, admitiendo la existencia de consentimiento tácito en la modificación de las condiciones de trabajo cuando éstas han sido conocidas y toleradas por el empresario.

2. El problema se plantea en orden a si la Administración, cuando actúa como empresario, es decir como participante en una relación jurídico-laboral, puede consentir tácitamente, como cualquier empresario privado.

Por lo pronto cuando interviene la Administración pública también hay que distinguir entre actos expresos, actos tácitos y actos presuntos o silencio administrativo.

MARTín MATEo (20), en línea con la postura mantenida por GARCfA-TrEVIJANo, que había distinguido entre silencio, inercia y acto implícito, afirma que el acto tácito no puede consistir en un vacío en el obrar, de donde se infiere que no pueden existir actos tácitos

(19) Tratado de Derecho civil español, tomo IV, Madrid, 1946, pág. 21.

(20) $\alpha$ Actos tácitos y actividad autorizante», Revista Española de Derecho Administrativo, 4, pág. 23. 
por pura tolerancia, como consecuencia de situaciones de hecho surgidas ante la ausencia de reacción por parte de la Administración.

La mera ausencia de reacción de la Administración tampoco puede considerarse un silencio administrativo con trascendencia jurídica, ya que éste, como afirma Boquera Oliver (21), se basa en la ficción de que cuando la Administración no ha dicho nada, estando obligada a manifestarse, ha hecho una declaración positiva o negativa. Es decir, que el silencio es una pasividad de la que se infiere ex lege consecuencias jurídicas (22), pero no una pasividad de la que pretendan extraerse consecuencias no previstas en el Ordenamiento jurídico de una manera expresa.

Por otra parte ya se sabe que el silencio administrativo es una institución creada, en garantía de los administrados, para facilitarles el acceso a la vía jurisdiccional, creando la ficción de un acto administrativo recurrible. En general el silencio es desestimatorio o negativo.

Sólo en contados casos especiales, expresamente previstos en la Ley, se admite un silencio positivo, que tiene que ser restrictivamente interpretado. Puesto que constituye un principio básico de derecho, que hoy ha trascendido a la nueva regulación de las licencias en la Ley del Suelo y al Estatuto de Bases del Régimen local (23), que no es posible admitir tácitamente (24) concedido lo que era ilegal otorgar expresamente, o lo que de acuerdo con los 'condicionamientos existentes no era lógico conceder (25). El silencio administrativo positivo requiere el escrupuloso cumplimiento de los requisitos y formalidades legales y, en todo caso, siempre habrá que tener en cuenta que los consentimientos de la Administración requieren además la actuación de un órgano competente, que no puede obviarse por la vía irregular de una conducta ignorada o meramente tolerada.

Por otra parte merece la pena señalar que la Administración

(21) «Algunas dificultades en la actual regulación del silencio administrativo», en $R A P, 30$, pág. 100.

(22) Martín Mateo, id.

(23) Artículo 165.3 de la Ley del Suelo, modificada por Ley de 2 de mayo de 1975, y Base 40.5 del nuevo Estatuto del Régimen local.

(24) La Jurisprudencia baraja con confusión los conceptos de actos tácitos y actos presuntos.

(25) Sentencia 11 de octubre de 1973. Ar. 3582 y otras muchas. 
requiere en todo caso, y aun en el supuesto de que actúe en relaciones jurídicas no administrativas, un tratamiento especial.

La Administración pública no es una empresa, ni es dable configurarla como tal, sea cual sea la opinión que pueda mantenerse sobre la posible sustantividad de su actividad económica actual. Sin perjuicio, claro es, de aquellos supuestos en que los servicios se personifican, adquiriendo formas mercantiles, con personalidad jurídica independiente.

Ciertamente que la legislación laboral considera a la Administración como empresario, a sus específicos efectos (artículo 5 de la Ley de Contrato de Trabajo, etc.), pero no puede desorbitarse el concepto. Ya advirtió GonZÁlez NIETo que en la legislación laboral "empresa", "empresario» y "patrono" son conceptos equivalentes (26), de donde cabe inferir con toda lógica que una cosa es que la Administración sea el patrono de determinado personal laboral de sus plantillas, y otra cosa muy distinta que quepa darle el tratamiento jurídico que puede otorgarse a cualquier empresario privado.

\section{LOS PRONUNCIAMIENTOS DE LA SENTENCIA}

La sentencia del Tribunal Central de Trabajo que estamos comentando, se expresa con extraordinaria corrección, recogiendo las ideas expuestas y aplicándolas al caso que nos ocupa. A saber:

a) Recoge la particularidad de la presencia de la Administración local (no un empresario cualquiera) en la relación jurídicolaboral, y. la correcta interpretación de sus actos presuntos, afirmando:

"Que la especial naturaleza de la persona jurídico-pública, explica su peculiar manera de elaborar sus declaraciones de voluntad, determinada en la normativa reguladora de su régimen jurídico...; únicamente sería válida la reducción de la jornada, si la acordase a través del órgano corporativo competente y siguiendo el procedimiento legal, pero sin que en modo alguno quepa reconocer igual valor, por tratarse de persona jurídico-pública con un régimen especial, al estado de hecho contrario a la Ley».

b) Y mantiene la correcta interpretación del derecho adquirido en cuanto adquisición legítima, al señalar que, "admitir lo contra-

(26) «El personal de las Corporaciones locales ante las Reglamentaciones nacionales del trabajo», RevisTa DE ESTUdios DE LA VIDA Local, 65, pág. 640. 
rio equivaldría a erigir las corruptelas en fuentes de derechos», con lo cual se apunta a una concepción sustancialista del Derecho, incidiendo en soluciones acordes con la justicia material, sin dejarse impresionar por la más fácil solución de inclinar la balanza a favor de los recurrentes.

\section{CONCLUSION}

Al llegar a este punto, conviene señalar a modo de resumen, al. gunas ideas prácticas.

1. La Administración no puede ser considerada, en ningún caso, como un empresario cualquiera. Su carácter de persona jurídico-pública, y los altos fines a los que sirve, exigen un tratamiento específico y diferenciado, incluso cuando se trate de relaciones jurídicas no administrativas.

2. ${ }^{a}$ Cuando la Administración interviene en una relación jurídico-laboral, hay que tener en cuenta el carácter tuitivo del Derecho laboral y el principio in dubio pro operario. Pero también hay que tener en cuenta las exigencias que comporta la presencia de la Administración en la relación jurídica. Siguiendo a GARRIDo Falla (27) diríamos que el interés público tiene que actuar siempre como standard o criterio de interpretación.

3. ${ }^{a}$ En el caso de los derechos adquiridos por el personal laboral al servicio de las Corporaciones locales, deberían centrarse fundamentalmente en los aspectos económicos de la relación. En el aspecto organizativo no se puede admitir una extensiva aplicación del concepto, que coarte el poder reorganizatorio de los servicios.

En ningún caso deben considerarse derechos adquiridos las meras situaciones iregulares, o las corruptelas contra legem. Los derechos deben nacer siempre de un acto administrativo expreso. No se pueden inducir de silencios o pasividades.

4. ${ }^{\mathrm{a}}$ La distinción existente entre personal funcionario y personal laboral al servicio de las Corporaciones locales, requiere un profundo replanteamiento.

Esta diferencia, dentro de la función pública, no está funcionalmente justificada, en muchos supuestos. Debería tenderse, como idea general, a una regulación uniforme de todos los servidores

(27) «La Administración y el método jurídico», RAP, 35, pág. 72. 
de la Administración pública, sometiéndolos a un idéntico estatuto jurídico.

5. Esta regulación uniforme no podría hacerse sobre la base de efectuar una regresión en las ventajas conseguidas por el personal laboral, a través de un Derecho tuitivo y protector.

Antes al contrario hoy se clama por una incorporación al estatuto funcionarial de aquellas ventajas. El fenómeno fue ya advertido por Pérez SERrano, al comienzo de la década de los años 1950 (proletarización del funcionario) y a él se han referido posteriormente numerosos autores (28). Por mi parte he tratado de romper una lanza recientemente a favor de la aplicación a los funcionarios locales de determinados principios tuitivos extraidos del Derecho laboral (29).

6. Finalmente debe advertirse que el presente trabajo señala ideas generales y criterios de interpretación. Pero cada caso concreto tiene sus matices específicos. Hay que tener en cuenta, como afirma GARCía DE ENTERRf́a (30), "la significación esencial que para el derecho tiene, y no puede menos de tener, el problema o el caso concreto".

(28) Puede verse una referencia más extensa al tema en el trabajo de JUNQURRA, a propósito de la nueva Ley de Seguridad Social de Funcionarios Civiles del Estado (Documentación Administrativa, 164, marzo-abril 1975).

(29) aLa aplicación de la legislación laboral a los funcionarios locales», Boletín de Información Municipal de Sevilla, núms. 10-11 (Sección doctrinal).

(30) eReflexiones sobre la Ley y los principios generales del Derecho», RAP, 40. 


\section{RESEÑA DE SENTENCIAS}

SUMARIO: I. ACTO ADMINISTRATIVO: 1. NULIDAD Y ANULABILIDAD. 2. LESIVIDAD.-II. BIENES: EXONERACIÓN FISCAL DE LOS COMUNALES.III. CONCEJALES: 1. PÉRDIDA DEL CARGO: CóMPUTO DE LAS SESIONES a LAS QUE SE Falta. 2. PÉRdida DEL CARGo: RECURSO CONTENCIOSO-ADMINISTRATIVO.-IIV. EXPROPIACION FORZOSA: 1. JUSTIPRECIO. 2. JUSTIPRECIO: PERJUICIOS POR DIVISIÓN DE FINCA. 3. JUSTIPRECIO: CONCESIÓN DE aguas.-V. FUNCIONARIOS: 1. PENSIÓN DE ORFANDAD. 2. PENSIONES: actualización. - VI. HACIENDAS LOCALES: 1. ARBitrio de PluSVAlfa: EXPLOTACIÓN aGRfCOLA. 2. ARBITRIO DE PLUSVALfa: PRESCRIPCION. 3. CONTRIBUCIONES ESPECIALES. 4. CONTRIBUCIONES ESPECIALES: ASOCIACIÓN DE CONTRIBUYENTES. 5. DERECH OS Y TASAS: CONTENEDORES EN LA VIA PÚBLICA. 6. EXENCIÓN INDEBIDA: DECLARACIÓN DE LESIVIDAD.VII. JURISDICCION CONTENCIOSO-ADMINISTRATIVA: APELACIÓN: ACUERdO MUNICIPAL FUERA DE PLAZO.-VIII POLICIA MUNICIPAL: 1. Ruina: causas. 2. Ruina: concepto. 3. Ruina: competencia PaRa DEClaraRla. 4. RuINa: MOTIVOS DE TAL SITUACIÓN. 5. RUINA: OBLIGACIÓN MUNICIPAL AL EFECT0. 6. RUINA: VALOR DE LOS DICTÁMENES PERICIALES. - IX. PROCEDIMIENTO ADMINISTRATIVO: DICTAMEN DE LETRAdO PREVIO AL ACUERDO DE INTERPOSICIÓN DE RECURSO.-X. SEGURIDAD SOCIAL AGRARIA.-XI. SERVICIOS: TRANSPORTES COLECTIVOS URBANOS.-XII. URBANISMO: 1. EDIFICIOS MONUMENTALES

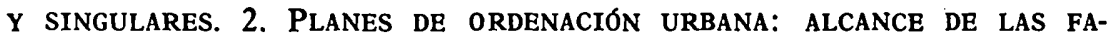
cultades de la administración. 3. Planes especiales. 4. Planes forMULAdOS POR PARTICULARES: CONTROL DEL AYUNTAMIENTO. 5. EJECUCIÓN DEl Plan: Realización de obras a petición de UN PaRticular.

\section{ACTO ADMINISTRATIVO}

\section{NULIDAD Y ANULABILIDAD}

Considerando: Que dentro del concepto genérico de invalidez de los actos administrativos es casi unánime la opinión que distingue dos categorías, o grados, la nulidad absoluta o de pleno derecho que presupone una gravísima conculcación de la legalidad vigente y la nulidad relativa o anulabilidad que implica una infracción de menor entidad, teniendo declarado, a este respecto, la doctrina jurisprudencial, que por conocida es ocioso citar, que el artículo $4 .^{\circ}$ del Código civil es inaplicable a la esfera administrativa, ya que las nulidades absolutas y rela- 
tivas en este campo del derecho están reguladas en los artículos 47 y 48 de la Ley de Procedimiento administrativo, limitando las nulidades de pleno derecho a las comprendidas en el primero de dichos preceptos, aparte de aquellos otros casos en que expresamente se establezca tal sanción, siendo la regla general la anulabilidad, y la excepción, la nulidad. (Sentencia de 26 de junio de 1975, Ar. 3.604).

\section{LESIVIDAD}

Es de desestimar el motivo invocado por la parte demandada de nulidad del acto declaratorio de lesividad al no haber requerido la Corporación demandante informe del Consejo de Estado, ya que con ello se confunde el mecanismo o procedimiento de la revisión de oficio, regulado con tecnicismo depurado, por primera vez, en los artículos 109 y 110 de la Ley de Procedimiento administrativo de 17 de julio de 1958, especialmente, después de la reforma operada por la Ley de 2 de diciembre de 1963, pues en dichos preceptos se regula la potestad anulatoria de los actos en vía administrativa, en tutela y garantía del interés público, consagrando la preceptiva intervención del más Alto Cuerpo consultivo de la Administración española, con informe favorable, en los supuestos previstos en el artículo 109 (nulidad plena de los actos comprendidos en el artículo 47 de dicha Ley) y en el artículo 110 (actos que infrinjan manifiestamente la Ley), en los que la intervención de dicho organismo es preceptiva, como ya se ha dicho, mientras que en los restantes impera con plena vigencia el proceso especial contenciosoadministrativo de lesividad, previa declaración en este sentido por la Administración dentro del plazo de cuatro años; por tal razón no es aplicable la doctrina sentada por la Sala $4 .^{a}$ del Tribunal Supremo, de fecha 3 de octubre de 1973, pues en ella, resolviendo las dudas y cavilaciones que en la esfera local había provocado la vigencia o no vigencia de los artículos 109 y 110 de la Ley de 17 de julio de 1958, supletoria de la Ley de Régimen local, en tanto en cuanto no se acomodase ésta a las prescripciones de la primera, nuestro más Alto Tribunal de Justicia, declara la procedencia de dicha aplicación supletoria, pero únicamente en los supuestos de específica revisión de los actos administrativos en los casos comprendidos en el artículo 109, en relación con los artículos 47 y 110, núm. 1, de la Ley de Procedimiento administrativo, no aplicables al proceso de lesividad regulado en el artículo 391 de la Ley de Régimen local, posteriormente reformado o afectado por la promulgación de la Ley rectora de esta jurisdicción. (Sentencia de 27 de octubre de 1975, Ar. 3.822).

\section{BIENES}

\section{EXONERACIÓN FISCAL DE LOS COMUNALES}

Considerando: Que los artículos 188 de la Ley de Régimen local y 6. del Reglamento de Bienes de las Entidades locales disponen que 
los bienes comunales no están sujetos a tributación del Estado, y en los artículos 24, 4, de la Ley de 23 de julio de 1966, así como en el artículo $60^{\circ}$. del texto refundido de la Contribución territorial rústica y pecuaria de la misma fecha, se dispone que gozarán de exención permanente y objetiva de la contribución rústica los bienes comunales, en relación con cuyos bienes el artículo 674 de la Ley de Régimen local claramente establece que la exención se entenderá concedida "de oficion, sin perjuicio de la acción inspectora del Ministerio de Hacienda; de donde resulta, por consiguiente, que dicha exención se concede en forma automática, sin necesidad de previa petición ni incoamiento de expediente alguno, lo que no contradice ni rectifica la Orden de 31 de mayo de 1965, que no tiene otra finalidad que determinar la competencia de los distintos órganos administrativos para conocer de los expedientes que se incoen por razón de exenciones, bonificaciones y desgravaciones en materia de contribución territorial, cuando para obtenerlas sea necesaria previa petición y la incoación del oportuno expediente conforme a la legislación vigente, con anterioridad a la entrada en vigor de la mencionada Orden; pero si así no fuese y existiera la supuesta contradicción, o la Orden implicase una modificación, es claro que en virtud del principio de seguridad jurídica o jerárquica normátiva, contenido en el artículo 17 del Fuero de los Españoles y en los 25 y 26 de la Ley de Régimen jurídico de la Administración del Estado de 26 de julio de 1957, habría que dar preferencia a lo dispuesto en los preceptos legales citados sobre los dados en la referida Orden, en atención al distinto rango de ambas disposiciones. (Sentencia de 5 de julio de 1975, Aranzadi 3.101).

\section{CONCEJALES}

\section{PÉRdida del CARGo: CómpUto DE. LAS SESIONES a laS QUE SE FALTA}

La cuestión queda en realidad circunscrita a decidir si el proceder indicado está o no subsumido en la causa que como determinante de la pérdida del cargo de Concejal estatuye el número 1 del artículo 81 de la vigente Ley de Régimen local (conforme, al cual el cargo de Concejal se perderá cuando, sin causa justificada, se deje de asistir a seis sesiones consecutivas), o en la segunda del artículo 36 del Reglamento ya indicado (que discrepa del anterior al establecer que el cargo de Concejal se perderá "por la falta de asistencia, sin causa justificada, a seis sesiones consecutivas o a diez no consecutivas en el término de doce meses, acreditadas con certificación del Secretario en relación con el libro de actas»), o más concretamente si los preceptos expresados se refieren única y exclusivamente a las sesiones del Ayuntamiento pleno - tesis propugnada por la parte actora-, o si, por el contrario, refiérense a las sesiones del Ayuntamiento y a las de la Comisión Permanente (tesis esta última que, sin fundamentar, aparece aplicada en la resolución del Gobierno civil), llegando la Sala a la conclusión de que 
tanto el precepto legal como el reglamentario que dejamos transcritos refiérense única y exclusivamente a las sesiones del Ayuntamiento pleno. (Sentencia de 21 de junio de 1975, Ar. 3.540).

\section{PÉRDIDA DEL CARGo: RECURSO CONTENCIOSO-ADMINISTRATIVo}

Si bien es cierto que el artículo 36, número 3, del expresado Reglamento dispone que «las cuestiones que se produzcan sobre la pérdida del cargo de Concejal serán declarados por las Corporaciones y resueltas por los Gobernadores civiles conforme al artículo 382 de la Ley", y que este último precepto establece que «contra la resolución de los Gobernadores civiles podrá recurrirse en alzada ante el Ministro de la Gobernación, sin que quepa ulterior recurso", no es menos exacto que la frase "sin ulterior recurso" refiérese a los recursos administrativos, pero no a la vía jurisdiccional, cuya exclusión exige una declaración expresa según taxativamente dispone el artículo $40, f$ ), de la Ley reguladora, y lo corrobora la doctrina jurisprudencial cuando al interpretarlo nos dice que "para estimar que, en virtud de esta norma, está excluido del recurso contencioso un acto que, formal y materialmente, sea administrativo es preciso no sólo que la exclusión la verifique una ley formal y no disposición de rango inferior, sino que terminantemente se indique en tal ley que determinados actos o resoluciones quedan exceptuados o excluidos del recurso contencioso, no bastando con decir que contra ellos no cabe recurso alguno, que no son susceptibles de recurso u otras semejantes, pues en tales supuestos se estima que sólo están prohibidos los recursos gubernativos o administrativos, pero no el contencioso propiamente dichon (sentencia de 26 de abril de 1958, Sala 5.a); que la expresión "sin ulterior recurso», frecuentemente consignada en las disposiciones administrativas, sólo pueden referirse a la vía gubernativa, porque para que alcanzara a la jurisdiccional sería preciso ser inequívoca y expresamente excluyente (sentencias de 26 de enero de 1960, Sála 4.a , y 17 de febrero de 1960 , Sala 5. ${ }^{a}$ ), que la prohibición del acceso a la revisión jurisdiccional sólo puede derivarse de un precepto expreso de esta Ley de la jurisdicción o de otra Ley referente a la materia que se pretende excluir (sentencia de 27 de octubre de 1959, Sala $4 .^{a}$ ), por lo que cuando contra un acto administrativo se dice que no se dará recurso alguno, la prohibición ha de entenderse limitada a los recursos administrativos, pero no al judicial ante las Salas de lo Contencioso, pues esta exclusión ha de establecerse expresamente por una disposición legal concreta (sentencia de 21 de enero de 1966, Sala 4. ${ }^{a}$ ). (Sentencia de 21 de junio de 1975, Ar. 3.540).

\section{EXPROPIACION FORZOSA}

\section{JUSTIPRECIO}

El instituto expropiatorio debe aspirar a dejar totalmente indemnizado el sujeto pasivo del mismo y, por tanto, en situación económica 
de poder sustituir su propiedad por otra similar, ya que la expropiación no es un acto voluntario entre dos contratantes, sino coactivo para una de ellas, el expropiado, que ha de aceptar la transmisión de su propiedad, sin más posibilidades que la de defender la indemnización correspondiente en la forma que las leyes establecen. (Sentencia de 4 de noviembre đe 1975, Àr. 3.748).

\section{JUSTIPRECIO: PERJUICIOS POR DIVISION DE FINCA}

Estimar la reclamación de perjuicios que indudablemente se producen en cada una de las fincas, al ser atravesadas por el camino, dividiéndolas, rompiendo la uniformidad de su cultivo, dificultando su laboreo y haciendo más difícil el acceso a algunas de las partes en que resultan divididas (sentencias del Tribunal Supremo de 14 de noviembre de 1958, 8 de noviembre de 1962, 26 de enero de 1963 y 17 de noviembre de 1971). (Sentencia de 5 de noviembre de 1975, Ar. 3.751).

\section{JUSTIPRECIO: CONCESION DE AGUAS}

ConsIDERANDo: Que el aprovechamiento fue concedido el 1 de agosto de 1902, en la cantidad de caudal de 1.000 litros por segundo y una altura de la presa de tres metros, que eran en el momento de la expropiación los datos inscritos en el Registro de Aprovechamientos de Aguas Públicas y que es la potencia que debe ser calculada, pues de lo contrario se infringe el artículo 409 del Código civii, en relación con la Ley de Expropiación forzosa, ya que éstos eran los límites del derecho de la entidad expropiada adquiridos por la concesión, supuesto que es el caudal concedido e inscrito el que tiene la posibilidad de utilizar el concesionario, al tratarse de un bien económico que se halla dentro de su patrimonio, según los términos de la concesión, aunque no se haya empleado toda la potencia concedida por el beneficiario del salto, sin que frente a este dato pueda oponerse una menor utilización, pues si la Administración entendía que el caudal utilizable era menor que el concedido, lo pertinente ara la rectificación del Registro de Aprovechamientos, cosa que no hizo al comprobar el 31 de enero de 1953 que el concesionario no obtenía toda la potencia de que el salto era capaz, pero sin que llegase a tomar medida alguna, por lo que, con arreglo a la constante jurisprudencia de esta Sala (sentencias de 18 de febrero de 1966, 7 de octubre de 1968, 21 de marzo de 1970, 7 de abril de 1971, etcétera), debe indemnizarse no el caudal realmente aprovechado por el concesionario, sino el susceptible potencialmente de utilización, inscrito a favor de éste. (Sentencia de 16 de octubre de 1975, Ar. 3.489). 


\section{FUNCIONARIOS}

\section{PENSIÓN DE ORFANDAD}

CONSIDERANDo: Que fallecido el padre de la recurrente, funcionario municipal, el 10 de marzo de 1962 causó pensión a favor de su viuda, y al morir ésta solicitó la hija hoy demandante pensión de orfandad, planteándose la cuestión de determinar si la cuantía de dicho haber pasivo ha de calcularse tomando como base el sueldo regulador computable que sirvió de módulo para la fijación de la pensión actualizada de viudedad de su madre, con arreglo a la Ley 108/63, o ha de ser el reconocido por la Munpal, que es el correspondiente anterior a dicha actualización, problema que ha sido resuelto por la jurisprudencia de la Sala (sentencias de 11 de marzo, 18 de abril, 6 de mayo de 1974, etc.) en el sentido de que la base y el porcentaje de la pensión ordinaria de orfandad del sueldo regulador, prevenidos en el artículo 49 de los Estatutos de 12 de agosto de 1960 , no son aplicables a las huérfanas mayores de veintitrés años que no justifiquen hallarse imposibilitadas para el trabajo, que son los requisitos exigidos por el artículo 48 de dicho texto para ser considerada huérfana a los efectos legales, por lo que careciendo la interesada de derecho al percibo de pensión de esta clase, no lo tiene tampoco a la actualización solicitada, que es una consecuencia de su condición de beneficiaria, conservando únicamente el derecho adquirido, con arreglo a la Disposición adicional 4. ${ }^{a}$ de la Ley de 12 de mayo de 1960, a mantener sus pensiones de la forma establecida en dicho precepto, que es el reconocimiento efectuado por la Administración correctamente, por lo que procede la desestimación del recurso sin hacer expresa imposición de costas. (Sentencia de 6 de no viembre de 1975, Ar. 3.768).

\section{PENSIONES: ACTUALIZACION}

Considerando: Que impugnándose por la Mutualidad Nacional de Previsión de la Administración Local, en el presente recurso, la $\mathrm{Re}$ solución del Ministerió de la Gobernación, de fecha 23 de junio de 1971, que declaró que para el cálculo de la pensión de orfandad de doña Dolores M. G., hija del que fue funcionario del Ayuntamiento de Melilla y jubilado en 30 de junio de 1930, "deberán computarse dos quinquenios acumulativos», procede desestimar el recurso al encontrarse ajustada a derecho conforme a la reiterada doctrina de la Sala (sentencias, entre otras, de 28 de marzo de 1974 y 22 de octubre de 1975) de que las pensiones causadas por funcionarios municipales antes de 1 de julio de 1963 y las que se causen en lo sucesivo, se determinarán o actualizarán tomando como haber regulador el que los causantes hubiesen consolidado en activo, según la legislación vigente a la sazón, si los cargos o puestos de trabajo hubiesen estado dotados con los emolumentos 
que ahora corresponden, constituidos, entre otros conceptos, por el aumento gradual de quinquenios sobre el sueldo correspondiente al tiempo de servicios efectivos prestados día por día, a tenor de los artículos 1., 2, y 10, 2, de la Ley de 20 de julio de 1963 y las Ordenes del Ministerio de la Gobernación de 2 y 22 de abril de 1964, cumpliéndose así la finalidad deseada por la legislación de actualización de pensiones de observarse la más posible equiparación entre los haberes pasivos referentes a situaciones iguales, pero de diversas épocas. (Sentencia de 24 de octubre de 1975, Ar. 3.557).

\section{HACIENDAS LOCALES}

\section{ARbitrio de Plusvalfa: explotación agrícola}

CONSIDERANDo: Que hallándose en principio sometida al arbitrio toda transmisión de terrenos y siendo excepcional la exención, que solamente se da cuando concurren las circunstancias descritas en el propio artículo 510 de la Ley de Régimen local (sentencia de 26 de junio de 1973), corresponde a los particulares interesados y no a los Ayuntamientos el demostrar que los terrenos de que se trate están dedicados a una de las expresadas explotaciones, como han declarado, entre otras, las sentencias del Tribunal Supremo de 14 de mayo y 9 de junio de 1965, 29 de marzo de 1966, 28 de abril, 26 de junio y 3 de noviembre de 1969, 8 de mayo de 1970, 28 de febrero y 6 de julio de 1973 y 22 de enero de 1974, en aplicación de las normas sobre carga de la prueba contenidas en los artículos 114, 1, de la Ley general tributaria y 1.214 del Código civil.

Considerando: Que en el caso de autos los actuales propietarios de los terrenos cuya transmisión mortis causa motiva el arbitrio objeto de discusión en este proceso, apoyan su petición de exención en la afirmación de constituir dichas fincas parte integrante de una explotación agrícola. Ahora bien, el concepto de explotación agrícola no coincide con el de la finca rústica, ya que, como dice la sentencia de $28 \mathrm{de}$ febrero de 1973, la exención de lo que nace es de la real explotación, concepto jurídico elaborado en principio por el Derecho privado, que contempla una realidad social preexistente con especial significado económico; pero no del fundo o de la finca que simplemente merezca la calificación de rústica, pues explotación es unidad de producción agrícola en la que se combinan factores de producción, entre ellos la tierra, que con la utilización de técnicas adecuadas de agricultura tiende a la producción de bienes generalmente proyectados hacia el mercado y con el elemento adicional de determinado riesgo. Esta diferencia entre finca rústica y explotación, de la que existen claros ejemplos en Derecho extranjero, tras los atisbos de la Ley de Arrendamientos rústicos, del Reglamento hipotecario y de la Ley de Concentración parcelaria, ha tomado carta de naturaleza en nuestro Derecho tributario al definir la 
Ley de Reforma tributaria de 1964, como explotación agrícola, cualquier extensión de terreno, compuesto o no de varias parcelas, siempre que constituyan una unidad orgánica, que en forma técnicamente autónoma tenga por objeto la producción agrícola o forestal, en la que concurra una actividad del titular y un riesgo asumido por el mismo (art. 72). (Sentencia de 14 de octubre de 1975, Ar. 3.655).

\section{ARbitrio de Plusvalfa: PRESCRIPCión}

Considerando: Que acordada la liquidación litigiosa el 3 de marzo de 1971, cuando ya había transcurrido el plazo de cinco años a que se acaba de hacer referencia, la Corporación municipal alega la interrupción del plazo prescriptivo por virtud de notificación formal llevada a cabo con fecha 26 de mayo de 1969, por lo que es preciso examinar si dicha notificación reúne los requisitos formales exigidos para que surta efecto, teniendo en cuenta que según el citado artículo $796,1, b$ ), de la Ley de Régimen local, para que la interrupción produzca efecto se requiere que el acto de investigación, y lo mismo en caso de reclamación, sea con conocimiento formal del obligado, por lo que no basta en el presente caso la publicación por edictos o en periódicos locales, debiendo de realizarse según el artículo 313 del Reglamento de Organización, Funcionamiento y Régimen jurídico de las Corporaciones locales, aprobado por Decreto de 17 de mayo de 1952, en el domicilio del interesado, recogiendo su firma en el duplicado, con indicación del lugar, día y hora en que la recibe, y si no supiere firmar lo hará quien lo represente o dos testigos presenciales mayores de edad, por lo que la notificación que consta en el folio 3 del expediente por correo certificado, practicada en domicilio distinto del actual de la apelada y recibida por persona con firma ilegible, cuya identidad y relación con la sociedad interesada no consta, no puede surtir los efectos formales exigidos por el citado precepto, resultando también inobservadas las prescripciones de la Ley de Procedimiento administrativo para las notificaciones, según su artículo 80, que ordena, para el caso de no encontrarse el interesado en el momento de entregarse la notificación, que se pueda hacer cargo de la misma cualquier persona que se encuentre en el domicilio y haga constar su parentesco o la razón de permanencia en el mismo, requisito no concurrente en modo alguno en la diligencia verificada en domicilio distinto, sin hacer constar ninguna de tales circunstancias respecto a la persona firmante del recibo del requerimiento, y sin que la diligencia obrante al folio 4, ni la carta, no adverada, acompañada a la demanda pueda subsanar tales omisiones, pues no se atienen a los citados preceptos, razones por las que, ante la falta de notificación formal de requerimiento, no cabe estimar interrumpido el plazo de prescripción de cinco años, reiterando la doctrina de esta Sala en orden a requisitos formales de las notificaciones, establecida en su sentencias de 24 de enero de 1972 y 20 de octubre de 1973, entre otras. (Sentencia de 13 de octubre de 1975, Ar. 3.473). 


\section{CONTRIBUCIONES ESPECIALES}

Pasando ahora al estudio del fundamental problema planteado en esta segunda instancia, es a saber: si en la cifra global del coste de las obras, a cubrir mediante contribuciones especiales, es lícito incluir el importe de las indemnizaciones que el Ayuntamiento debe satisfacer para la expropiación de edificios y otras construcciones; importa asimismo reconocer que sobre el mismo tema controvertido en este pleito -contribuciones especiales por las obras del proyecto de ensanche y urbanización de la calle de Aragón, de la ciudad de Vigo- ya se ha pronunciado esta Sala en su reciente sentencia de 14 de junio de 1975, que resuelve afirmativamente la cuestión, en consonancia con lo que asimismo se declara en la de 10 de octubre de 1973 y en las demás que en aquélla se citan, sentando, entre otros, como puntos de doctrina -que entiende la Sala deben reiterarse ahora-, en primer lugar, que el artículo 117 de la Ley del Suelo sólo es aplicable en el sistema de cooperación, ajeno al caso de litigio, en que el seguido por cierto es el de cesión de viales, y en segundo lugar, que al no corresponder las obras municipales a proyecto alguno de "nueva urbanización», sino a nuevas obras de «urbanización parcial», recobran todo su imperio los artículos 131, 144 y 154 de la Ley de Régimen local, que resuelven el problema planteado en los términos en que lo hace la sentencia objeto de esta apelación. (Sentencia de 24 de septiembre de 1975, Ar. 3.278).

\section{CONTRIBUCIONES ESPECIALES: ASOCIACIÓN DE CONTRIBUYENTES}

ConsIDERANDo: Que alegada por la recurrente, sin contradicción en el acto de la vista, haberse iniciado el expediente de imposición de contribuciones especiales y acuerdo fijando su cuantía, siquiera fuese pro visional, cuando las obras habían sido realizadas, tal acuerdo impositivo resulta extemporáneo, pues los artículos 454 y 470 de la vigente Ley de Régimen local, al fijar los módulos para la valoración del coste total de las obras y el límite máximo de las contribuciones especiales en relación con dicho coste total, toman en cuenta la valoración y contribución en relación con un tiempo anterior a la realización de las obras y el mismo sentido de fijación anticipada de las referidas contribucio nes se desprende del fundamental artículo 465, cuyo número 1 prevé la constitución de la asociación de contribuyentes, "siempre que deba cubrirse mediante contribuciones especiales más de un tercio del coste total de alguna obra, instalación o servicio», además del supuesto de constitución voluntaria por acuerdo de determinada mayoría de interesados, y con la salvedad, que aquí no se da, de que no rebase la obra la cantidad de dos millones en Municipios de más de 100.000 habitantes, a que se refiere el número 2 del mismo precepto, por lo que tanto para el cálculo de los expresados límites en la contribución como para la necesaria constitución de la asociación es preciso que el acuer- 
do, fijando la cuantía de la imposición, sea anterior a la realización de la obra, sin que con posterioridad pueda fijarse tal determinación, que carecería de objeto, ya que la finalidad de la asociación comprende la inspección de la obra al tiempo de su ejecución, como autoriza el artículo 26 del Reglamento de Haciendas locales, y como quiera que el Ayuntamiento no se atuvo a este orden normal de determinación de cuotas, sino que el acuerdo que las fija provisionalmente es posterior a la ejecución de las obras, según su afirmación no contradicha por el mismo, tal actuación resulta contraria a la finalidad legal de permitir una intervención de los contribuyentes fiscalizadora de las obras a las que van a contribuir de modo especial, por lo que carecen de validez los acuerdos municipales impugnados, reiterando la doctrina de esta Sala, establecida, entre otras, en sus sentencias de 30 de marzo de 1970 y 25 de octubre de 1971. (Sentencia de 2 de octubre de 1975, Ar. 3.343).

\section{DERECH OS Y TASAS: CONTENEDORES EN LA VIA PÚBLICA}

Hay que partir de la indiscutible premisa de que la ocupación de la vía pública mediante los contenedores de referencia reúne los requisitos exigidos por el artículo 435, 2, de la Ley de Régimen local, para constituir hecho imponible de la tasa por aprovechamientos especiales de los bienes municipales, por lo que sin duda alguna puede ser objeto de imposición al amparo del número 25 del artículo 444 de la misma Ley. (Sentencia de 22 de octubre de 1975, Ar. 3.798).

\section{EXENCIÓN INDEBIDA: DECLARACIÓN DE LESIVIDAD}

Procede declarar la lesividad y nulidad de tal acto, pues la Ley de Régimen local, texto refundido de 24 de junio de 1955, establece en su artículo 719 , letra $a$ ), "que la obligación de contribuir es siempre general en los límites de esta Ley, y, en su consecuencia, ni aquellas Corporaciones ni el Gobierno podrán declarar otras exenciones que las concretamente previstas y autorizadas en ella, debiendo tenerse por expresamente derogada toda exención actualmente en vigor, aunque se funde en razones de equidad, analogía o equivalencia o en especial consideración de clase o fueron, reiterando dicho precepto, en su letra d) "que, salvo lo especialmente dispuesto en esta Ley en materia de conciertos, aportaciones o auxilios, será nulo todo pacto, contrato o sistema que acuerden las Corporaciones loocales y que tengan por objeto la obligación de contribuir, la forma o la cuantía de las exacciones», normativa confirmada en el número 3 del artículo 217 del Reglamento de Haciendas locales. (Sentencia de 27 de octubre de 1975, Aranzadi 3.822 ). 


\section{JURISDICCION CONTENCIOSO-ADMINISTRATIVA}

\section{APELACIÓN: ACUERdo MUNiCIPAL FUERA DE PLAZO}

ConsIDERANDO: Que por lo que respecta al Ayuntamiento recurrido y ahora también apelante cabe decir lo mismo, aunque por distinta causa, pues al interponerse el recurso de apelación por su Procurador dentro del plazo de los cinco días, el 4 de diciembre de 1973, según acredita la diligencia del Secretario receptor del escrito, falta, no obstante, el acuerdo de recurrir de la Comisión Municipal Permanente del indicado Ayuntamiento para tener por debidamente interpuesta esta apelación, ya que, como se dice en las sentencias de esta misma Sala de 17 de noviembre de 1972 y más concretamente en la de 24 de abril del mismo año, las facultades de dicha Comisión municipal para agilizar la brevedad procesal de estos recursos, a tenor del apartado i) del artículo 122 de la Ley de Régimen local, debió acordarse la interposición del presente dentro del plazo de cinco días, y como en el rollo de esta apelación aparece certificado el acuerdo del Ayuntamiento Pleno de mantener la apelación interpuesta anteriormente, es claro que al tomarse este acuerdo el 4 de enero de 1974 queda fuera del plazo impugnatorio, sin que pueda convalidarse tal omisión, puesto que los plazos son improrrogables y caducan después de su transcurso, conforme establece el artículo 121 de la Ley jurisdiccional invocada, al no acreditarse el acuerdo de la Comisión Municipal Permanente en tal sentido. (Sentencia de 14 de mayo de 1975, Ar. 3.241).

\section{POLICIA MUNICIPAL}

\section{RUINA: CAUSAS}

Como tiene dicho la Sala $4 .^{\text {a }}$ del Tribunal Supremo según constante jurisprudencia (sentencias de 15 de abril, 17 de mayo y 20 de diciembre de 1968, entre otras), de los diferentes supuestos que el artículo 170 de la Ley del Suelo y Ordenación urbana contempla, para que una finca pueda ser declarada en estado ruinoso, basta la presencia de cualquiera de ellos para su declaración (sentencia de 17 de febrero de 1970). (Sentencia de 14 de mayo de 1975, Ar. 3.244).

\section{RUINA: CONCEPTO}

La declaración de ruina de un inmueble, toda vez que la situación de ruina es objetiva y no se establece en beneficio del propietario, sino de las personas moradoras en el edificio y de los viandantes que por sus proximidades han de circular, constituyendo una actividad de policía de seguridad, encomendada al Municipio, para preservar de daños a las personas y a los bienes amenazados por el peligro de derrumbamiento que tal situación de ruina comporta, supone, cual ha manifestado el Tribunal Supremo, la inoperancia, a efectos de declarar ruinoso 
un inmueble de la culpabilidad en tal estado del propietario arrendador o de cualquier otro propjetario (sentencias de 6 de octubre de 1961, 22 de diciembre de 1965 y 12 de mayo de 1966, entre otras), sin que por ello exista contradicción con la normativa del Derecho privado, ni específicamente de la Ley de Arrendamientos urbanos y Ley del Suelo, que se invoca por el recurrente, ya que, sin desconocer tal normativa, el arrendatario pudo, en su tiempo, ejercitar las acciones conducentes a la defensa de sus derechos. (Sentencia de 3 de junio de 1975, Ar. 3.322).

\section{RUINA: COMPETENCIA PARA DECLARARLA}

CONSIDERANDO: Que como motivo básico de la pretensión ejercitada en este proceso - - la segunda instancia se abunda en el razonamiento ya desplegado ante el Tribunal a quo-viene referido con carácter prioritario a determinar si los Alcaldes como Presidentes de los Ayuntamientos disponen de facultades, competencia, para resolver los expedientes contradictorios de ruina en los supuestos normales; esto es, al margen de los casos de urgencia y peligro (ruina inminente acordada en expediente no contradictorio) y que la sentencia de instancia afirma con olvido de la doctrina jurisprudencial contenida en las sentencias de este Tribunal de 10 de mayo de 1969, 23 de junio de 1970 y 5 de octubre de 1974 , etc.

CONSIDERANDo: Que, por el contrario, siguiendo el criterio ya expuesto en la sentencia últimamente citada, hemos de reiterar aquí y ahora el juicio negativo frontalmente expuesto en la sentencia de 10 de mayo de 1969 (implícitamente acogido en la sentencia de 11 de octubre de 1973), en cuanto sostiene que las dudas y vacilaciones que sobre el problema suscitaba la Ley de Régimen local (artículos 116, 121 y 122 , en concordancia con el número 10 del artículo 114 de la Ley de Arrendamientos urbanos), quedaron resueltos a través de lo normado en el artículo 170 de la Ley del Suelo, y de las sentencias citadas, al proclamar que nada se opone a la competencia de la Comisión Permanente (sentencias de 7 de julio de 1961, 29 de febrero de 1962, 9 de mayo de 1969, 26 de enero de 1973, etc.), dado que en el artículo dicho de preferente y concreta aplicación en materia de ruina de edificios se distingue claramente entre las declaraciones de ruina en expedientes contradictorios y las declaraciones de inminente urgencia, ya que la primera decisión corresponde a los Ayuntamientos, en su Comisión Permanente, según el sentido jurisprudencial y por el procedimiento adecuado, atribuyendo prudencialmente a un órgano colegiado y no unipersonal la responsabilidad de la resolución, tanto por garantía de los administrados como por descargo de la primera autoridad municipal respecto a tan trascendente decisión, con independencia de que a la Alcaldía corresponda la dirección de la tramitación del expediente con arreglo a lo dispuesto en los artículos 58 de la Ley de Régimen local, 290 del Reglamento de Organización y Funcionamiento y demás preceptos concordantes; cuestión la expuesta completamente distinta de la declaración de ruina inminente (número 4 del artículo 170 de la 
Ley de 12 de mayo de 1956), en cuyo supuesto ha de atenderse a la «urgencia y peligron, señalando una tramitación simple o de urgencia (distinta de la que corresponde a un expediente contradictorio y con diversa finalidad y alcance) con atribución de competencia, bien al Ayuntamiento o a la Alcaldía; conclusión, por otra parte, inquirida con apoyo en una exégesis gramatical y sistemática del precepto (artículo 170 citado), dado que si la Ley establece una distinción patente, otorgando únicamente al Ayuntamiento facultades para declarar la ruina (párrafo $1.0^{\circ}$ ), y a éste y a la Alcaldía para intervenir y decidir los supuestos de urgencia, el Alcalde, como autoridad unipersonal, no parece investido de competencia para resolver los expedientes contradictorios, ya que en otro caso no tendría explicación lógica la alusión a «el Alcalde» en el mencionado número 4 del artículo 170 de la Ley, puesto que si en el concepto "Ayuntamiento» del número 1 está incluido también el Alcalde (como órgano municipal que es), huelga la mención del mismo en el supuesto excepcional; en consecuencia, una interpretación razonable del precepto exige formular la siguiente declaración: no se trata de una reiteración innecesaria, sino de una consciente atribución de competencia a órganos municipales diversos en razón de supuestos de intervención de diferente naturaleza jurídica. (Sentencia de 18 de junio de 1975, Ar. 3.511).

\section{RUINA: MOTIVOS DE TAL SITUACIÓN}

La jurisprudencia de este Tribunal, de manera reiterada y uniforme, viene sancionando que «son indiferentes a la jurisdicción contenciosoadministrativa los motivos que hayan traído como consecuencia a un estado ruinoso de las fincas, por ser necesario prescindir de las causas productoras de aquélla y de la consecuencia no de culpa por parte del arrendador, dado que el fin de policía de seguridad que aquí se persigue obliga a soslayar actividades precedentes y centrar la observación en la realidad objetiva en un momento determinado, sin que, por otra parte, la decisión del recurso prejuzgue la cuestión, ajena a este procedimiento, de las responsabilidades en que pueda haber incurrido la propiedad de la finca por la alegada y supuesta incuria en su conservación"; más que suficiente todo lo sustentado para declarar la improcedencia de la apelación impulsada. (Sentencia de 18 de abril de 1975, Ar. 2.561).

\section{RUINA: OBLIGACIÓN MUNICIPAL AL EFECTO}

Los términos del artículo 170 de la Ley sobre Régimen del Suelo obligan imperativamente a la Administración a declarar el estado ruinoso de edificios cuando se dé alguna de las circunstancias que menciona, y la Administración viene obligada a hacerlo, en cumplimiento de la función de policía de personas y cosas que le imponen los artículos 116 de la Ley de Régimen local y 389 del Código civil, como ha declarado el Tribunal Supremo en doctrina de excusada cita por su reitera- 
ción, sirviendo por todas las demás la sentencia de 9 de mayo de 1972, según la cual la falta de realización de unas obras por la propiedad de la finca "podrá jugar a efectos civiles de exigencia de tal reparación o de la consiguiente responsabilidad, residenciando la cuestión ante los Tribunales de orden civil, pero sin que tal conducta pueda ser relevante a efectos de la declaración de ruina del inmueble, toda vez que esa situación (de ruina) es objetiva y no se establece en beneficio del propietario, sino de las personas moradoras del edificio y de los viandantes que en sus proximidades han de circular, constituyendo una función de policía de seguridad encomendada al Municipio, en cuyo sentido se ha manifestado el Tribunal Supremo al afirmar la inoperancia, a efectos de declarar la ruina de un inmueble, de la culpabilidad en tal estado de propietario arrendador o de cualquier otro propietario", pudiendo citarse las sentencias de 3 de abril de 1957, 25 de febrero de 1959, 6 de octubre de 1961, 22 de diciembre de 1965 y 12 de mayo de 1966. (Sentencia de 5 de mayo de 1975, Ar. 2.660).

\section{RUINA: VALOR DE LOS DICTÁMENES PERICIALES}

La Sala 4. ${ }^{\text {a }}$ del Tribunal Supremo, en su sentencia de 28 de enero del pasado año, ratificando la doctrina contenida en las anteriores de 1 de febrero y 10 de junio de 1969 y 9 de noviembre de 1970, ha declarado que la ruina es una pura situación de hecho, debiendo estarse a lo que las probanzás ofrezcan, y por la índole de las cuestiones a justificar, los dictámenes periciales adquieren una importancia decisiva y trascendente, de aquí que los emitidos por técnicos desligados de las partes, arquitectos municipales o designados en el proceso por insaculación, por su innegable garantía, objetividad e independencia han de prevalecer sobre los aportados por los interesados, por cuanto es de suponer en los de aquéllos mayor objetividad en la apreciación de circunstancias concurrentes y no menor imparcialidad en sus conclusiones (sentencias de 29 de enero de 1971 y 5 de noviembre de 1970). (Sentencia de 6 de mayo de 1975, Ar. 2.662).

\section{PROCEDIMIENTO ADMINISTRATIVO}

\section{Dictamen de LETRAdo PREvio al acuerdo DE INTERPosición DE RECURSO}

Se trataba del recurso que un Ayuntamiento entabló contra resolución de la MUNPAL.

La doctrina jurisprudencial imperante en esta materia viene a permitir la subsanación referida, pero condicionándola a que no pase de la mera acreditación documental del preceptivo dictamen jurídico, porque no deja de insistirse por las diversas Salas de lo Contencioso de este Alto Tribunal, que, aun en estos supuestos, es necesario que el dictamen de Letrado se hubiera emitido antes del ejercicio de la pretensión, esto es, para precisar más el concepto, antes de la presentación 
del escrito de interposición del recurso jurisdiccional, que es lo que nos viene a decir la sentencia de 19 de junio de 1961, siguiendo una línea precedida y continuada por otros fallos (sentencias de 25 de abril de 1947, 12 de febrero de 1949, 1 de diciembre de 1953, 17 de diciembre de 1954, 4 de mayo de 1961, 9 de diciembre de 1962, 17 de febrero, 22 de mayo y 26 de octubre de 1968), sin que falten resoluciones que llegan a exigir que la formulación del tan repetido dictamen hubiera tenido efecto antes incluso del acuerdo de la Corporación de ejercitar el recurso (sentencia de 19 de noviembre de 1959); en resumen, y por lo expuesto, se impone la inadmisibilidad del presente recurso, con la consiguiente imposibilidad de entrar en el enjuiciamiento del fondo de la litis. (Sentencia de 10 de noviembre de 1975, Ar. 3.859).

\section{SEGURIDAD SOCIAL AGRARIA}

Considerando: Que la fijación de cuota, objeto de este pleito, corresponde al ejercicio de 1967, en que era plenamente aplicable, en su re dacción primitiva, la Ley de Seguridad Social de 31 de mayo de 1966, por to que, al no ser posible tener en cuenta, ahora, por falta de retroactividad expresa, las disposiciones legales y reglamentarias posteriores a la citada Ley, las que han tenido total vigencia a las que a los efectos que aquí pudieran interesar, después del ejercicio de 1971, es indudable que, en el caso presente, y sin adelantar en absoluto futuras soluciones, hay que mantener las dos primeras fundamentales que sirven de soporte al fallo apelado, y que son: carácter económica. administrativo inicial de la cuestión surgida con motivo de la fijación de cuotas antes referida, por la asimilación que el artículo 46 de la Ley de 31 de mayo de 1966 hace a la contribución rústica y pecuaria, y exigencia del binomio "empresario-trabajador» para el consentimiento al pago de la cuota empresarial que se configura en 1966 como auténtico seguro obligatorio. (Sentencia de 3 de junio de 1975, Ar. 2.619).

La sentencia de 14 de mayo de 1975 (Ar. 3.247) dice:

La cuestión objeto del mismo viene a estar constituida por la de determinar si el Ayuntamiento de Teruel, demandante del mismo, viene obligado en cuanto que es titular de determinados montes públicos que los explota mediante régimen normal de subastas y que reúne a su vez la condición de sujeto pasivo de la contribución territorial debe o no cotizar por el Régimen de Seguridad Social Agraria, cuestión la expuesta que ha venido a ser la de numerosos recursos conocidos y resueltos por esta Sala a través de las respectivas sentencias, como son entre otras las de 23 de febrero de 1967, 23 de marzo de 1971, 26 de febrero y 27 de diciembre de 1972, por todas las cuales se vino a sentar la doctrina de que los Ayuntamientos, en tal supuesto, no reúnen la condición de empresarios y por ello procede la exención de la cuota empresarial agraria de los Ayuntamientos, doctrina que, tanto por lo acertada de la misma, según resulta de las consideraciones que se ex- 
ponen en las respectivas citadas sentencias, como por exigencia del principio de unidad de la doctrina que resulta del apartado $b$ ) del número 1 del artículo 102 de la Ley de la Jurisdicción, se impone seguir en el presente.

La sentencia de 20 de octubre de 1975 (Ar. 3.479) consigna:

Considerando: Que la fijación de cuota, objeto de este pleito, corresponde al ejercicio de 1967, en que era plenamente aplicable, en su redacción primitiva, la Ley de Seguridad Social de 31 de mayo de 1966, por lo que, al no ser posible tener en cuenta, ahora, por falta de retroactividad expresa, las disposiciones legales y reglamentarias posteriores a la citada Ley, las que han tenido total vigencia a los efectos que aquí pudieran interesar después del ejercicio de 1971; es indudable que, en el caso presente, y sin adelantar en absoluto futuras soluciones, hay que mantener las dos premisas fundamentales que sirven de soporte al fallo apelado, y que son: carácter económico-administrativo de la cuestión surgida con motivo de la fijación de cuota antes referida, por la asimilación que el artículo 46 de-la Ley de 31 de mayo de 1966 hace a la contribución rústica y pecuaria, y exigencia del binomio «empresario-trabajador» para el sometimiento al pago de la cuota empresarial que se configura en 1966 como auténtico seguro obligatorio; todo lo cual conduce a confirmar íntegramente la sentencia objeto del presente recurso de apelación.

\section{SERVICIOS}

\section{TRANSPORTES COLECTIVOS URBANOS}

CONSIDERANDO: Que el transporte colectivo de viajeros por autobús constituye un servicio típico de la competencia municipal (artículos 101 y $102, e)$, de la Ley de Régimen local), siempre que se limite su prestación al casco urbano, ya que la legislación especial sobre transportes mecánicos por carretera (Ley de 27 de diciembre de 1947, artículo 1. Reglamento de 9 de diciembre de 1949, artículo 1.०; sentencias del Tribunal Supremo de 4 de diciembre de 1969, 21 de febrero y 21 de marzo de 1970, entre otras) no sólo ha vaciado la competencia municipal sobre los transportes que hayan de realizarse en el término municipal, pero fuera del casco urbano, sino que apodera expresamente a la Administración central para delimitar este casco en aquellos casos en que no sea posible aplicar el criterio de continuidad en la edificación. (Sentencia de 9 de mayo de 1975, Ar. 3.213).

\section{URBANISMO}

\section{EDIFICIOS MONUMENTALES Y SINGULARES}

El artículo 46, número 1, declara que serán nulas las reservas de disposiciones que se contuvieren en los Planes de Ordenación, así como 
las que con indepedencia de ellos se concedieren, salvo que lo fueren para edificios «monumentales» o «singulares», circunstancia que no concurre en el complejo residencial a que esta litis se refiere, bastando para ello con expresar lo que según la jurisprudencia entiende por edificios de esa clase, y así la sentencia de 9 de noviembre de 1974 prescribe que esta facultad de dispensar sólo puede interpretarse restrictivamente como excepcional que es, circunscribiéndola a los edificios que respondan al concepto indeterminado de «singulares» o de "monumentales", lo cual supone una diferencia sustancial con las construcciones ordinarias y excluye la aplicación de criterios simplemente cuantitativos en su calificación, razón por la que sólo debe reputarse edificio singular aquel que por su propia naturaleza y fines difiera esencialmente de las construcciones ordinarias que componen la ciudad, y también en este sentido la sentencia de 22 de mayo de 1974 manifiesta que los tipos de edificios monumentales responden a unos cánones científicos y de apreciación artística y se peculiarizan por un conjunto de normas dentro y fuera de la Ley del Suelo, en el sentido más amplio de monumentos urbanos, y son, por tanto, distinguibles por unos criterios que radicalmente difieren de las construcciones comunes; y análogamente a lo que ocurre con los monumentos, el propio significado del vocablo «singulares» es empleado en el sentido de extraordinario, distinto de lo común y poco frecuente, lo limita a algo más que lo que difiere de las construcciones ordinarias que componen el conjunto urbano, precisión importante porque excluye el criterio simplemente cuantitativo de edificación que por su gran volumen, altura, riqueza de aspecto, etc., excede notablemente de las limitaciones establecidas en el lugar donde se pretende emplazar, ya que no es la prohibición de las formas respecto de un edificio que las excede notablemente lo que determina a deno minarle "edificio singular» para poder dispensarlas, sino que es la verdadera singularidad de una construcción, tal como por vía de ejemplo es la destinada a cuartel, estación férrea o de autobuses, museo, etc., que llevan el concepto hacia el sentido tan excepcional que debe tener la misma y que por ello permite dispensar aquellas limitaciones impuestas a las demás, pues lo contrario llevaría a generalizar la aplicación de la dispensa, que es excepcionalísima por constituir derogación de un principio general y convertirla en una discrecional relajación de las normas cada vez que se pretenda levantar un edificio que rebasase las po sibilidades permitidas por las Ordenanzas y precisamente por el hecho de pretenderlo en mucha mayor medida que otras. (Sentencia de 27 de junio de 1975, Ar. 3.607).

\section{Planes de oRdenación URBana: alCANCE de las facultades DE LA AdMINISTRACIÓN}

CONSIDERANDo: Que el hecho de que la parcela cuestionada tuviere antes de la formulación del Plan aprobado el carácter de solar edifica- 
ble, aún no demostrado plenamente por el recurrente (que se limitó a aportar fotocopias de unas comunicaciones municipales sobre cierto so lar no plenamente identificado con éste) seria en todo caso irrelevante para determinar la ilegalidad del Plan en el punto cuestionado, puesto que es mediante este instrumento como la Administración delimita el derecho a edificar de los particulares (artículo 70 de la Ley del Suelo), con potestad legal para determinar la inedificabilidad de ciertas partes del suelo al destinarlas a viales y zonas verdes en los Planes (artículos $9 . \circ, 1, b)$, y $10,1, c)$, potestad que, si se da originariamente, puede referirse también a la revisión de los Planes prevista en los artículos 37 y 39 , en cuanto esta actuación revisora no se diferencia sustancialmente de la actividad planificadora inicial; todo ello, naturalmente, sin perjuicio de las consecuencias derivadas de la justa distribución de los beneficios y cargas de la ordenación entre los propietarios, a tenor del artículo 70, 3. (Sentencia de 17 de abril de 1975, Ar. 2.557).

\section{Planes espectales}

Considerando: Que en consecuencia de cuanto se expone, el Plan Parcial especial a que este recurso se refiere, si bien obedece a la iniciativa particular para una nueva urbanización, y, por tanto, la Administración sólo interviene en principio para aprobarlo previa comprobación de que reúne las correspondientes formalidades legales y después vigilar que las obras se realizan con sujeción al mismo; sin embargo, no pueden prevalecer aspectos especulativos ni beneficiosos de tipo privado en detrimento de los importantes y necesarios fines públicos a que obedece el Urbanismo, según se deduce de la vigente Ley del Suelo, que trata de esta clase de planes de iniciativa privada, cuya nota característica es precisamente la especialidad de la ordenación, que, sin embargo, no viene a desvirtuar el régimen de los mismos, que es el general establecido, con las consiguientes peculiaridades impuestas por su contenido, y de ahí el que deberán estar en dependencia y armonía con los intereses superiores de la colectividad, y por consiguiente deben dar cumplimiento a las respectivas normas urbanísticas de general aplicación, puesto que es tarea actual procurar la ordenación urbana sin detrimento grave de la naturaleza, logrando así la defensa del paisaje y la proliferación en suma de los espacios verdes, lo cual alcanza una dimensión insospechada, cuyo objetivo debe tenerse muy en cuenta en este aspecto de la moderna regulación urbanística, pues, en definitiva, es preciso aspirar a que se logre un punto de equilibrio que permita la continuidad del desarrollo urbano $\mathrm{y}$, al mismo tiempo, la deseable conservación de la naturaleza, armonizando la ecología y la arquitectura, y en su consecuencia, toda norma complementaria y subsidiaria del planeamiento debe tener el contenido impuesto por su propia naturaleza. (Sentencia de 27 de junio de 1975, Ar. 3.607). 


\section{Planes fORMUlados POR PARTICULARES: CONTROL DEL AyUNTAMIENTO}

CONSIDERANDO: Que abierto de este modo al examen de fondo del asunto, la cuestión fundamental planteada concierne a dilucidar si la distinción entre condiciones formales y de contenido, respecto a las legalmente exigidas a los planes presentados por particular, resulta en sí relevante en cuanto a asignar exclusivamente a las primeras las posibilidades de control administrativo sobre legalidad del acto de presentación o elevación al Ayuntamiento del Plan, de tal manera que, cumplidos que fueren los requisitos de forma, se halla por esta sola circunstancia vinculada la Corporación a otorgar la aprobación inicial, tesis que es la fundante de la sentencia apelada estimatoria del recurso, o bien, en opuesto sentido a la hermenéutica referenciada, puede y debe asimismo la Corporación examinar el contendo del plan propuesto y denegar la susodicha aprobación inicial si lo reputara en desacuerdo con las normas urbanísticas rectoras de aquel contenido, cuestión la asi enunciada que procede resolver, teniendo en cuenta en primer térmo que, a tenor del artículo 10 , párrafo $1 .^{\circ}$, en relación con los 32,40 y 42 de la Ley del Suelo, y según señaló esta Sala en sentencia de 14 de abril de 1971, el significado y alcance de los planes parciales no son otros que desarrollar el Plan General, con la implícita necesidad de ajustarse a lo que en éste se dispone como limitativo o preceptivo del contenido de los parciales, siendo condición para aprobarlos inicialmente que no se oponga al susodicho Plan General de Ordenación, de donde se infiere la necesidad de que ya en el momento de decidir si se incoa el especial proceso corresponda al Ayuntamiento el examen de contenido y consecuente denegación si aquel ajuste al Plan General no lo entendiera logrado, lo que es coherente con la observación de que ningún precepto impone a la Administración municipal el deber de hacer suya, a efectos de la ulterior instrucción procesal, una propuesta particular de planificación cuando a limine entiende que su redacción es conteste con el ordenamiento urbanístico vigente y aplicable al lugar acotado por el Plan parcial propuesto; y en segundo término, tampoco es admisible la tesis relacionada al principio, por cuanto que el invocado hacer suyo el órgano corporativo un Plan elevado a su aprobación inicial no consiste meramente en una libre adhesión volitiva a su fondo, sin otro límite que el de la observancia de los requisitos formales, sino en expresión de un positivo criterio de ajuste del contenido del Plan a las superiores normas urbanísticas a que se hubiese atenido la Corporación para confeccionarlo, pues si a tenor del artículo 32 de la Ley del Suelo la aprobación inicial la realiza el organismo o Corporación que lo hubiere redactado, y esta redacción atañe propiamente al contenido, sólo cabe entender que con la aceptación originaria del Plan presentado por el particular -máxime cuando no ha sido autorizado de acuerdo con el artículo 40, número 2- se califica aquél en idénticas condiciones a como si lo hubiese redactado o confeccionado la Corpo- 
ración, lo que implica no ya simple posibilidad, sino también necesidad de que el organismo municipal verifique el control de contenido de precedente referencia y deniegue la aprobación inicial, es decir, la apertura del proceso hacia la aprobación definitiva, si no cumple en este aspecto con la normativa vigente, sin perjuicio para el promotor particular de la instancia jurisdiccional contra el acto denegatorio si estimare que el planeamiento por él redactado es acorde con las referidas normas urbanísticas. (Sentencia de 16 de mayo de 1975, Ar. 3.248).

\section{EJecución del Plan: Realización de obRas a PETICión DE UN PARTICULAR}

Que la primera de las postuladas pretensiones entraña en definitiva un enjuiciamiento sobre la posibilidad de que un particular pueda denunciar la negligencia de los Ayuntamientos en el cumplimiento de sus obligaciones concernientes a urbanismo derivadas de las leyes y planes aprobados, imponiéndoles por vía jurisdiccional una determinada actividad consistente en la ejecución de una concreta obra ciertamente prevista en los aludidos planes, y planteada así la tesis en términos generales con base en la acción pública instaurada en el artículo 223 de la Ley del Suelo, es manifiesta su improcedencia, puesto que el desarrollo de la acción urbanizadora regulada en la Ley desenvuelta en los planes y proyectos, como estos propios nombres indican, nace con vocación de futuro y no puede ser ejecutada de manera instantánea, simultánea y general en todo el ámbito que comprende el Plan, ni mucho menos al son de intereses o exigencias de los particulares afectados, sino, muy al contrario, ordenada y sucesivamente, en consonancia con las necesidades demandadas por el interés público y posibilidades económicas para su financiación, y así lo evidencia ante todo la ausencia de una norma concreta que lo disponga terminantemente, pues no puede invocarse como tal la contenida en el artículo 44 en relación con el 45, que atribuye a los planes y proyectos el carácter de «inmediatamente ejecutivos» de muy distinto alcance y significación, y especialmente el conjunto de los preceptos que constituyen la legislación sobre la materia, en los que se establece que los planes generales se desarrollan en planes parciales mediante proyectos de urbanización y programas periódicos, con detalle de los sectores de interés preferente y su grado relativo de prelación entre sí, siendo, por otra parte, facultad discrecional del Ayuntamiento la elección del sistema de actuación y régimen de gestión de las obras; y estando en definitiva específicamente previstas en la Ley (artículos 205 y 206) las consecuencias de tal negligencia de los Ayuntamientos en el cumplimiento de sus obligaciones urbanísticas, que no es otra sino la de que tales obligaciones se transfieran a los organismos que previene su texto, de lo que se desprende, por supuesto, que la aludida actividad no puede serles coercitivamente impuesta por vía jurisdiccional a instancia de particulares interesados. (Sentencia de 13 de junio de 1975, Ar. 3.468). 